\title{
Two-Stage Pediatric Penile Reconstruction after Postcircumcision Gangrene
}

\author{
Tarek Zayid, MD ${ }^{1} \quad$ Mohamed O. Ouf, MD ${ }^{1}$ Amr Elbatawy, MD ${ }^{1}$ Serag M. Zidan, MD ${ }^{1}$ \\ Abdelnaser Hamdy, MD ${ }^{1}$ Hany Ismail, MD ${ }^{1} \quad$ Khallad Sholkamy, MD ${ }^{1}$ Hazem Dahshan, MD \\ Wael Ayad, MD ${ }^{1}$ \\ ${ }^{1}$ Department of Plastic Surgery, Al Azhar University, Cairo, Egypt \\ Address for correspondence Tarek Zayid, MD, EBOPRAS, Department \\ of Plastic Surgery, Al Azhar University, Cairo 11756, Egypt \\ J Reconstr Microsurg Open 2020;5:e95-e100. \\ (e-mail: dr.tarekzayid@hotmail.com).
}

\begin{abstract}
Keywords

- groin flap

- penile reconstruction

- tubularized scrotal flap

- circumcision

- penile gangrene

Background Postcircumcision penile gangrene is a devastating complication that may lead to total or subtotal penile loss requiring penile reconstruction. Pediatric penile reconstruction poses diverse challenges for most plastic surgeon.

Patients and Methods Retrospective cohort study of 12 children ranged from 6 to 36 months old suffered from total or partial penile loss secondary to electrocautery burn during circumcisions. Reconstruction was done by island groin flap for phallus in first stage and urethral reconstruction by tubularized scrotal flap 6 months later. The outcome was evaluated by assessment of flap survival, the esthetic appearance, urethral competence and rate of complication.

Results Follow-up was ranged from 6 to 24 months. A new phallus of satisfactory dimensions was achieved in all cases. Complications included partial necrosis of the flap in two cases, fistulas in two cases, and stenosis of the urethral anastomosis in one case. These complications were successfully resolved by corrective surgery. Good satisfactory result regarded as shape and urination stream.

Conclusion Penile reconstruction can be performed in children with good results and low complication rate. The use of island groin flap for phallus reconstruction followed by urethral reconstruction by tubularized scrotal flap 6 months later was found effective, time saving, and with minor complication.
\end{abstract}

Male circumcision is a religious and traditional ritual among billions today, making it one of the most common procedures performed worldwide. It has been estimated that $30 \%$ of males are circumcised. A wide range of surgical techniques is used for male circumcision, depending on the predominant surgical practice in the area and the specialty of performing surgeon or physician. ${ }^{1,2}$ Complications of male circumcision are minimal regarding incidence and severity; however, major complications can happen. ${ }^{3}$

Total or partial penile loss is a rare but devastating complication can happen due to circumcision. The main perpetrator in this complication is the use of monopolar electrocautery during circumcision. Some authors even forbid any use of electrocautery with clamp circumcision. ${ }^{4}$ Penile gangrene can be sever depending on the intensity of electric current carried by the small diameter of the penis, the generated heat causes gangrene of the penis ending into partial or total penile loss. ${ }^{5}$

The main goals of penile reconstruction include formation of a sizable neophallus and allowing normal urination. Reconstructive options are multiple; regional, distant flaps or free tissue transfers were described in literature. This wide range of reconstructive techniques is an indication that neither is perfect. $^{6}$

Pediatric penile reconstruction is much more controversial than in adults regarding indications and reconstructive techniques. It has been rarely performed until today. Gilbert received

June 24, 2020

accepted after revision

August 25, 2020
DOI https://doi.org/

10.1055/s-0040-1718717. ISSN 2377-0813.
Copyright $\odot 2020$ by Thieme Medical Publishers, Inc., 333 Seventh Avenue, New York, NY 10001, USA. Tel: +1(212) 760-0888.
License terms

()ㅇㅇㅛ $\Theta$ 
et $\mathrm{al}^{7}$ reported total phallic reconstruction in seven male children using one stage a free tissue transfer.

In our practice, we meet a considerable number of pediatric patients with partial or total penile loss due to postcircumcision gangrene. We chose to perform early penile reconstruction as primary coverage, taking in consideration the needed penile size after puberty, as well as providing the neopenis with enough bulk, to contain a neourethra that would permit voiding while standing. In this article, we reviewed our experience in pediatric penile reconstruction after gangrene related to circumcision complication.

\section{Patients and Methods}

Retrospective cohort study of 12 children, age ranged from 6 to 36 months, suffered from total or partial penile loss as a result of circumcision with monopolar diathermy, in the time between 2017 and 2019. (-Fig. 1). The phallic reconstruction was done in two stages: in the first stage, an extended island groin flap was used to cover the penile defect, and 6 months later, a urethral reconstruction was done by tubularized scrotal flap.

The following parameters were used to assess the postoperative outcome of phallus reconstruction: the flap survival, appearance of the penis and its ability to retain its shape, rate of complication of flap, and donor site morbidity. In addition, assessment of the urethral reconstruction was done by the ability of the patient to urinate while standing and rate of complications like fistula or stricture or complete failure.

\section{Operative Procedures}

All surgeries were done under general anesthesia with caudal block. Flap marking was done with the patient in the supine position starting with marking of femoral artery, inguinal ligament, pubic tubercle, and anterosuperior iliac spine. This is followed by locating and mapping of the superficial iliac circumflex artery with its superficial and deep branches using Doppler flow meter.

Surgery started with complete debridement of the amputation wound. This is followed by releasing of urinary opening with spongy body and the remaining two cavernous bodies till root of the penis

The flap is elevated from its lateral part proceeding medially in the subfascial plane. The deep branch of the superficial circumflex iliac artery is included in the flap by raising the Sartorius fascia with the flap medially. At this point, dissection continues slowly to avoid injury of the deep branch of the superficial circumflex iliac artery. Deepithelialization of 4 to $5 \mathrm{~cm}$ of the base of the flap is done to elongate the flap pedicle. This enables flap transposition into the region of the lower margin of pubic symphysis without tension.

A two-finger width subcutaneous tunnel is made at the lower margin of pubic symphysis. The pedicle can be then rotated approximately 180 degrees without compromising the blood supply of the flap followed by passing it through the subcutaneous tunnel. The flap is then sutured to itself to make a cylindrical shape with suture line anterior followed by suturing it to the remaining penile skin and to the stump of the cavernous bodies. In some cases, the flap was first wrapped
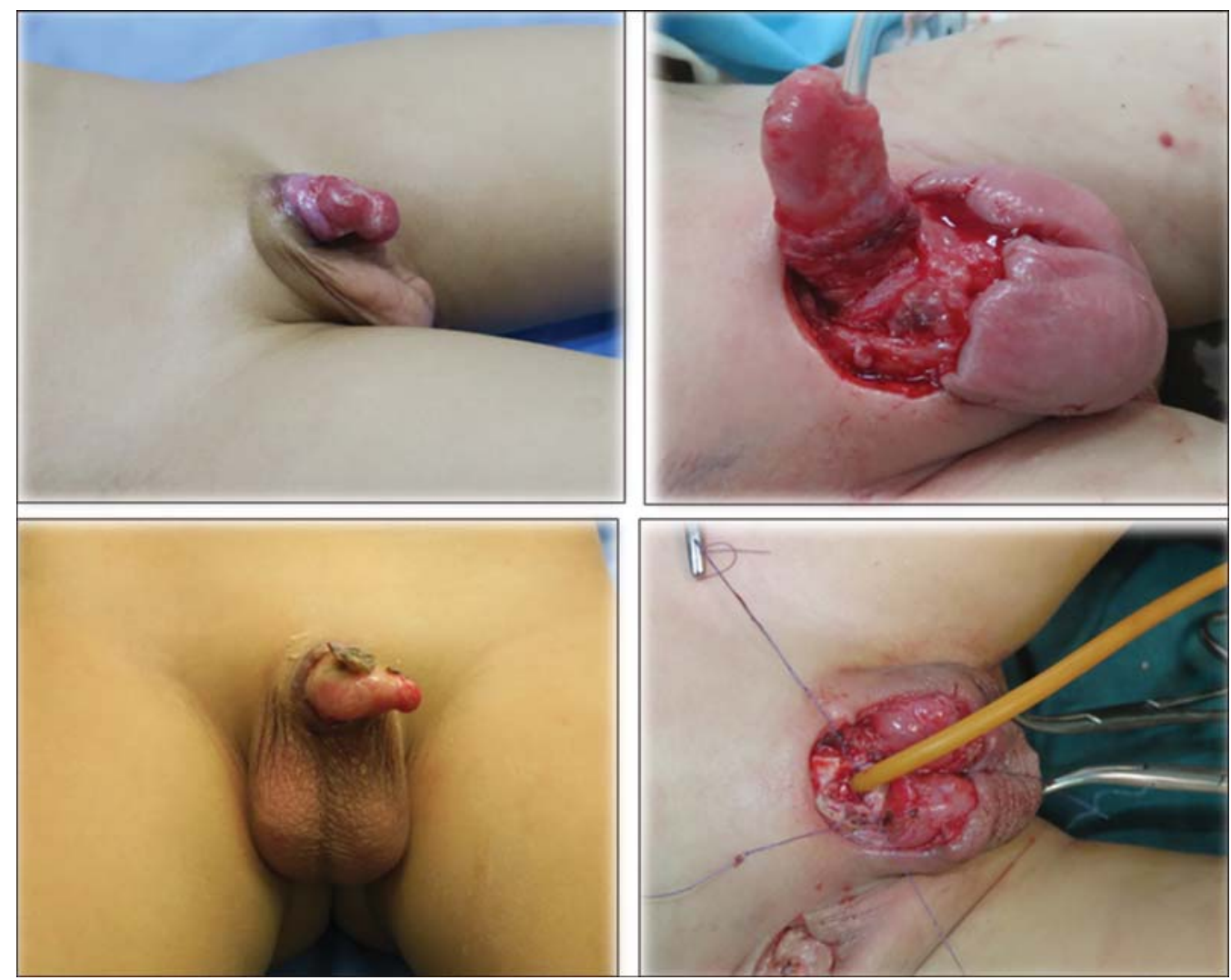

Fig. 1 Cases of postelectrocautery circumcision penile gangrene. 
around the remaining part of cavernous tissue and then tubed. The donor site skin defect can be easily closed by undermining and directly approximating the edges of the defect.

Postoperatively, the patient is kept in a semisupine position with the involved lower limb flexed at the hip and knee while keeping the reconstructed penis slightly elevated. Kinking of the pedicle is avoided by turning the flap contralateral to the donor area (-Fig. 2).

The urethral reconstruction was done 6 months later, by tubularized scrotal flap. The surgery was performed in the lithotomy position with the patient under general anesthesia with caudal or spinal block. The flap is designed as a perineoscrotal based 2-cm-wide rectangles, centered over the midraphe of the stretched scrotal skin. The skin strip was tubularized on a $10-\mathrm{Fr}$ catheter with 5/0 interrupted polyglycolic acid sutures with care taken to avoid eversion of the skin. This was followed by another layer of continuous polyglycolic acid sutures above the sutured edges; the tubularized flap was then interposed by rotating it on its perineal scrotal base. Proximal anastomoses with the remaining healthy urethra were performed with 5/0 absorbable interrupted sutures and the distal end sutured to the tip of the flap. Removal of catheter after one week (-Figs. 3, 4).

\section{Results}

Follow-up period ranged from 6 to 24 months (average, 17 months). All flaps survived completely apart from partial necrosis in two cases. A neophallus with satisfactory dimensions was achieved and it retained the size and shape during the follow-up period in all 12 patients. The penis is
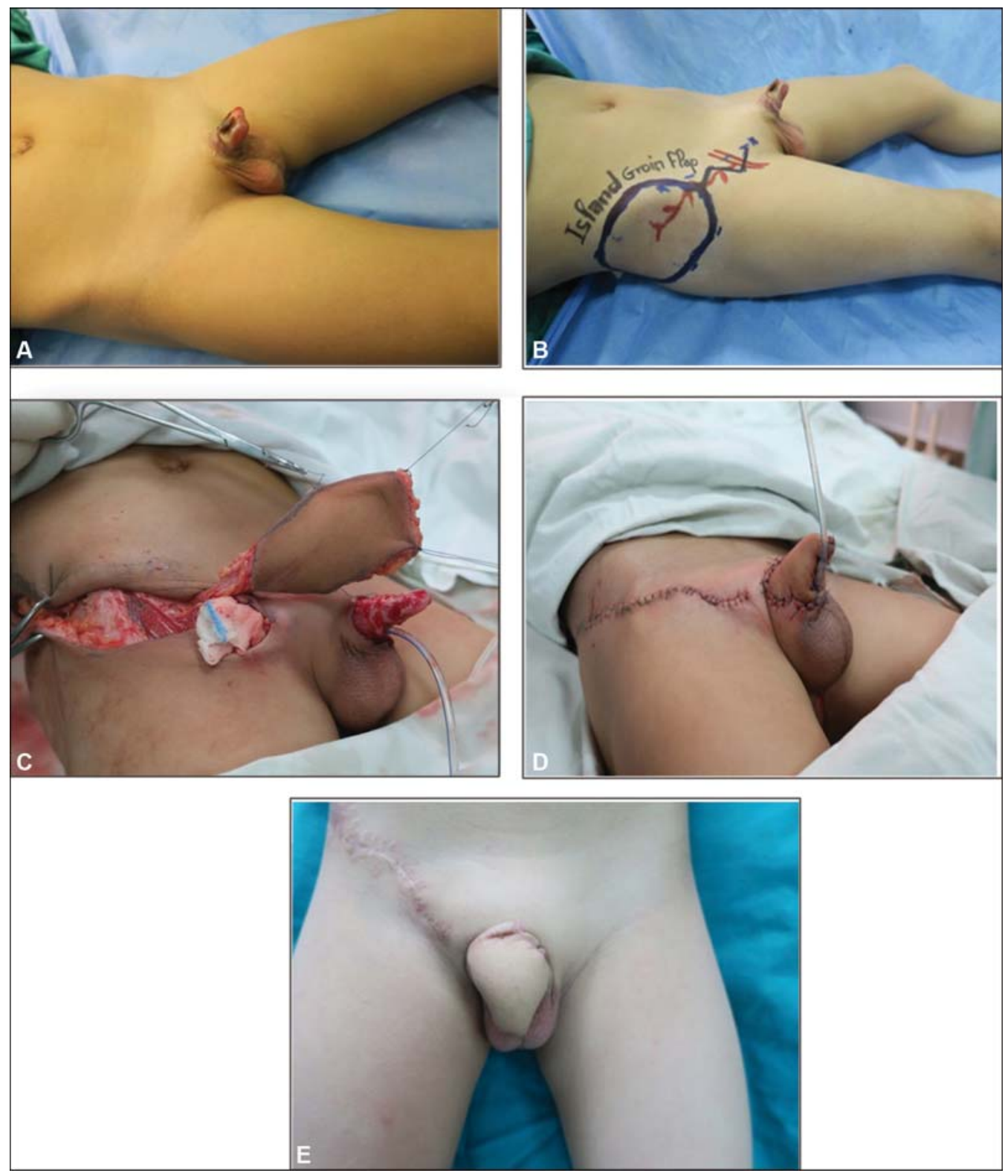

Fig. 2 First stage penile reconstruction. (A) A 3-year-old male child suffered from postelectro cautery penile gangrene with subtotal penile loss. (B) Marking of the island extended groin flap. (C) Elevation of groin flap and tunneled to reach penis. (D) Early postoperative result after penile reconstruction (E) late 6 months of postoperative result before second stage. 

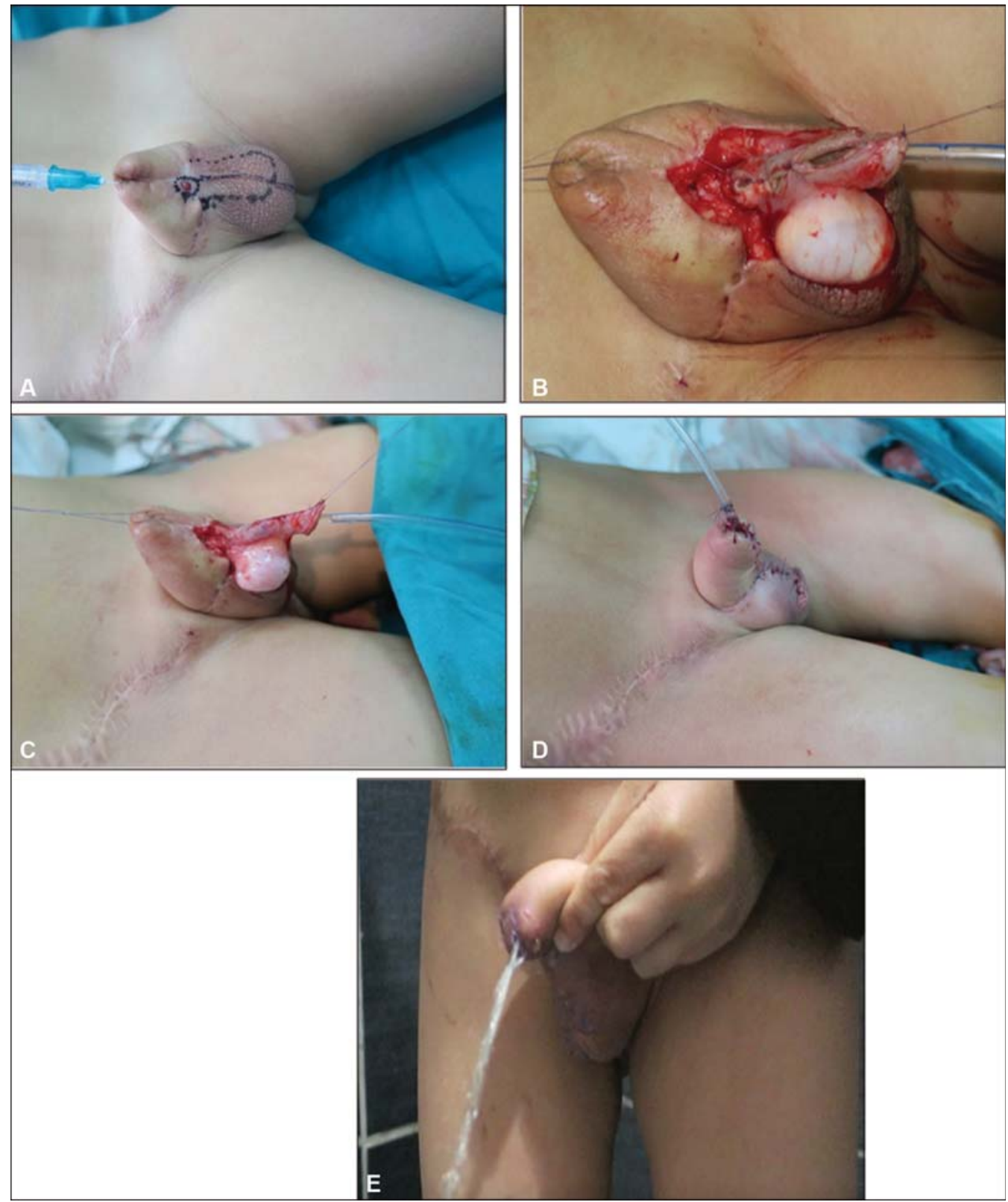

Fig. 3 Second-stage penile reconstruction. (A) Marking of scrotal flap centered over the mid raphe of the stretched scrotal skin. (B) Creation of the urethra around a nylton catheter. (C) After complete tabularization of the new urethra. (D) Early postoperative result after urethral reconstruction. (E) Late result while the patient urinates on standing position.

esthetically acceptable by the parents. Urethral competence and normal urination stream while standing was achieved.

Early complications included partial flap necrosis in two children and partial dehiscence of the donor site in three cases. Late complications included urethral stenosis at the anastomosis point in one case and urethrocutaneous fistulas in two cases. These complications were treated successfully by corrective surgery. Good satisfactory result regarded as shape and urination stream.

\section{Discussion}

Circumcision is an ancient surgical procedure being reported in ancient Egyptian texts. Circumcisions are done mainly for religious and traditional practice. It is a safe procedure with a low complication rate. Most complications are simple and may not even require specific treatment; however, postcircumcision penile gangrene is a devastating complication that may lead to total or subtotal penile loss, requiring penile reconstruction. ${ }^{8}$

Although there are many studies on penile reconstruction in adult, few reports are available for penile reconstruction in the early age group. In their report of 10-year experience of microsurgical penile reconstruction, Gilbert et $\mathrm{al}^{7}$ reported seven pediatric cases; however the earliest age he did was a 5year-old child. In our Series, we started the reconstruction earlier before the age of 3 years because in our country, circumcision is done at early age in the first or the second year of life.

Choosing the optimum techniques for penile reconstruction is difficult, especially in children. Although there are 


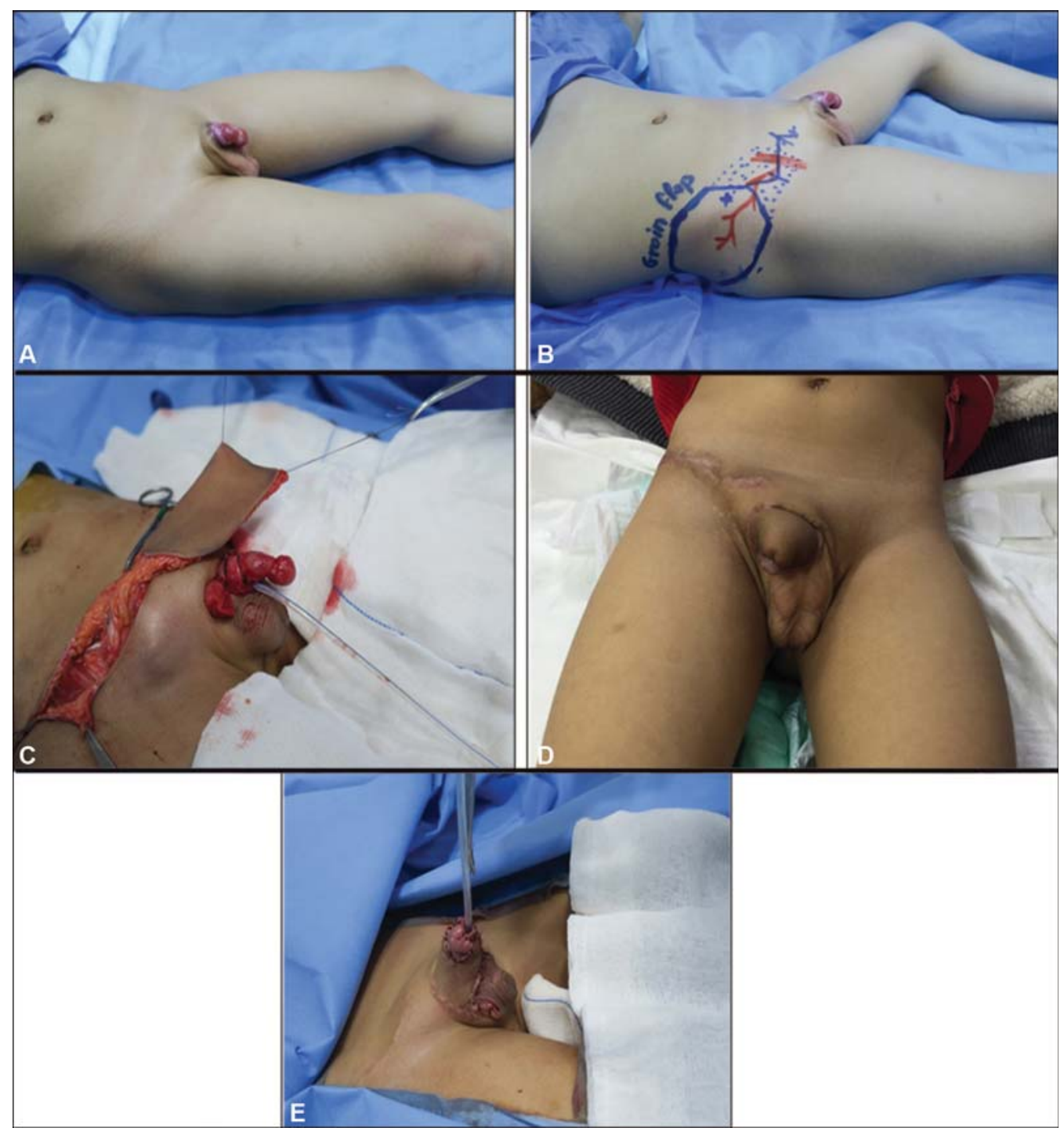

Fig. 4 (A) A 3-year-old male child suffered post electro cautery penile gangrene. (B) Marking of the island extended groin flap. (C) Elevation of groin flap and tunneled to reach penis. (D) Late 6 months of postoperative result before second stage. (E) Early postoperative result after urethral reconstruction.

important considerations regarding the quality of the neophallus, the donor site morbidity is an important factor to be given extra attention in pediatric reconstruction.

Reconstruction of a penis which would retain its long-term shape is an important consideration in pediatric reconstruction. For this reason, we have used an extended pedicle island groin flap for penile reconstruction in children. In the 1970s and early 1980s the groin flap was used for multistage phalloplasty. Sun and Huang ${ }^{9}$ introduced one-stage phalloplasty using a lateral groin skin flap with composite iliac crest. Since then, the use of the pedicled groin flap in single-stage phalloplasty was reported by many authors, but the technique was only used in adults. ${ }^{10,11}$

We changed some concepts in using groin flap in phallic restoration. This Include extending the flap, lengthening the pedicle, and deepithelialization of the proximal part of the flap to be tunneled under the bridge of skin between the pedicle and the penis. The extended pedicle island groin flap technique is an alternative to the most commonly used procedures today, like free tissue transfer. ${ }^{12,13}$ The extended groin flap carries the advantages of simple harvesting technique, short operative time, and low complication rate which make it the favorable option for pediatric reconstruction. ${ }^{14}$ Moreover, this flap has abundant tissue, reliable blood supply, and lymphatic drainage, as well as minimal donor site morbidity. ${ }^{15,16}$

Creation of the neourethra using a separate flap is the second component of successful penile reconstruction. ${ }^{7,11,17}$ We used tubularized scrotal flap for urethral reconstruction in a separate stage which is more advantageous than using the full-thickness skin graft. ${ }^{18}$ The rate of fistula in our study is $16.6 \%$ ( 2 of 12 patients). This is considered low when compared with rates in the literature. Biemer reported urethral fistulae in 9 of 14 patients after urethral reconstruction in spite of using vascularized tissue. ${ }^{18}$

A perineum-based pedicled flap was found to be a good option for urethroplasty due to multiple factors. First, the scrotal skin well tolerates contact with urine owing to the abundance of sebaceous glands; second, the flap has 
abundant double vascularity without liability to torsion or stretching; and third, anatomical contiguity, and tissue availability of the flap. ${ }^{18-21}$

Pediatric penile reconstruction should be fourth dimensional; taking future needs in consideration. Presence of penile sensation is crucial in adults, so it should be kept in mind while planning penile reconstruction in a child. In our study, sensation was preserved only in the proximal portion of approximately $2 \mathrm{~cm}$. Lack of sensation in distal parts is a notable problem following puberty. This problem could be overcome using sensate flaps carrying neurovascular pedicles. ${ }^{22}$

Penile reconstruction is performed in the children mainly for psychological reasons. The reconstructed phallus can put the patient in a sexual dilemma as the neophallus does not look exactly like the usual penis of his peers, in addition to the possible absence of erogenous sensibility and competent urethra. However, this dilemma is preferable to him than the psychological trauma of being without penis. ${ }^{23,24}$

The consideration of fourth dimension, namely, time and growth rates, raises the question about the growth of reconstructed phallus into adulthood. This is challenging as the growth rates differ between somatic and genital tissues in childhood. Somatic tissues grow on a linear scale, but genital tissues grow exponentially after hormonal stimulation begins with the onset of puberty. The surgeon should design a flap size that will grow into a suitable-sized phallus at puberty. Somatic growth and genital growth curves can be computed in percentile form, so that the relative flap size required at any age, expressed as a percentage of complete adult growth, can be established. ${ }^{25}$

Whenever penile reconstruction is indicated in children, it should be performed. Although not all our goals were achieved, we believe that it is important to complete as much of the reconstruction as possible. However, the reconstructed penis is functional as the patient has an effective urination, and the result was pleasant for the patient's parents. ${ }^{26}$

\section{Conclusion}

The extended pedicle island groin flap technique is an alternative to the most commonly used procedure today, that is, free tissue transfer. Due to simplicity of execution, time saving, and minor complications, it is especially useful in children. Urethral reconstruction with tubularized scrotal flap can be used in many ways. Because it reaches any segment of the urethra without tension, twisting, or stretching. Owing to its excellent vascularization, the risk of complications is minimal.

\section{Conflict of Interest}

None declared.

\section{References}

1 Wiswell TE, Tencer HL, Welch CA, Chamberlain JL. Circumcision in children beyond the neonatal period. Pediatrics 1993;92(06):791-793

2 Schoen EJ. The status of circumcision of newborns. N Engl J Med 1990;322(18):1308-1312
3 Hutcheson JC. Male neonatal circumcision: indications, controversies and complications. Urol Clin North Am 2004;31(03): 461-467, viii

4 Krill AJ, Palmer LS, Palmer JS. Complications of circumcision. ScientificWorldjournal 2011;11:2458-2468

5 Uzun G, Ozdemir Y, Eroglu M, Mutluoglu M. Electrocauteryinduced gangrene of the glans penis in a child following circumcision. BMJ Case Rep 2012;2012:x

6 Aköz T, Erdoğan B, Görgü M, Kapucu MR, Kargi E. Penile reconstruction in children using a double vascular pedicle composite groin flap. Scand J Urol Nephrol 1998;32(03):225-230

7 Gilbert DA, Jordan GH, Devine CJJ Jr., Winslow BH, Schlossberg SM. Phallic construction in prepubertal and adolescent boys. J Urol 1993;149(06):1521-1526

8 Peters RT, Fisher R. Paediatric circumcision using bipolar diathermy. Ann R Coll Surg Engl 2009;91(05):436

9 Sun GC, Huang JJ. One-stage reconstruction of the penis with composite iliac crest and lateral groin skin flap. Ann Plast Surg 1985;15(06):519-528

10 Mukherjee GD. Use of groin and mid-thigh flap in reconstruction of penis with penile and perineal urethra and a dorsal skin-lined socket for a removable prosthesis. Ann Plast Surg 1986;16(03):235-241

11 Persoff MM. Groin flap phallus reconstruction with new method of urethroplasty. Ann Plast Surg 1981;6(02):132-137

12 Yang M, Zhao M, Li S, Li Y. Penile reconstruction by the free scapular flap and malleable penis prosthesis. Ann Plast Surg 2007;59(01):95-101

13 Kropp B, Cohn JE, Wang W, Sokoya M, Ducic Y. Free tissue transfer penile reconstruction. Semin Plast Surg 2019;33(01):24-29

14 Puckett CL, Montie JE. Construction of male genitalia in the transsexual, using a tubed groin flap for the penis and a hydraulic inflation device. Plast Reconstr Surg 1978;61(04):523-530

15 Murakami R, Fujii T, Itoh T, et al. Versatility of the thin groin flap. Microsurgery 1996;17(01):41-47

16 Clodius L, Smith PJ, Bruna J, Serafin D. The lymphatics of the groin flap. Ann Plast Surg 1982;9(06):447-458

17 Perović S. Phalloplasty in children and adolescents using the extended pedicle island groin flap. J Urol 1995;154(2 pt 2):848-853

18 Biemer E. Penile construction by the radial arm flap. Clin Plast Surg 1988;15(03):425-430

19 Hayashi Y, Kojima Y, Kurokawa S, Mizuno K, Nakane A, Kohri K. Scrotal dartos flap for the prevention of the urethrocutaneous fistula on hypospadias urethroplasty. Int J Urol 2005;12(03): 280-283

20 Ligang Y, Yongxiong S, Yili T. One stage urethroplasty with midline scrotal flap with vessel pedicle for hypospadias. China J Mod Med 2003;(11):30

21 Carrera A, Gil-Vernet A, Forcada P, Morro R, Llusa M, Arango O. Arteries of the scrotum: a microvascular study and its application to urethral reconstruction with scrotal flaps. BJU Int 2009;103 (06):820-824

22 Sengezer M, Oztürk S, Deveci M, Odabaşi Z. Long-term follow-up of total penile reconstruction with sensate osteocutaneous free fibula flap in 18 biological male patients. Plast Reconstr Surg 2004;114(02):439-450, discussion 451-452

23 Hamill PVV, Drizd TA, Johnson CL, Reed RB, Roche AF, Moore WM. Physical growth: national center for health statistics percentiles. Am J Clin Nutr 1979;32(03):607-629

24 Schonfeld WA, Beebe GW. Normal growth and variation in the male genitalia from birth to maturity. J Urol 1942;48(06):759-777

25 Treharne RW. Review of Wolff's law and its proposed means of operation. Orthop Rev 1981;10:35

26 Assaf R, Albahhah T, Ayoub K, et al. Penile reconstruction using scrotal flap after usage of monopolar electrocautery in a 2month-old Syrian child: a case report. J Surg Case Rep 2019; 2019(12):rjz351 